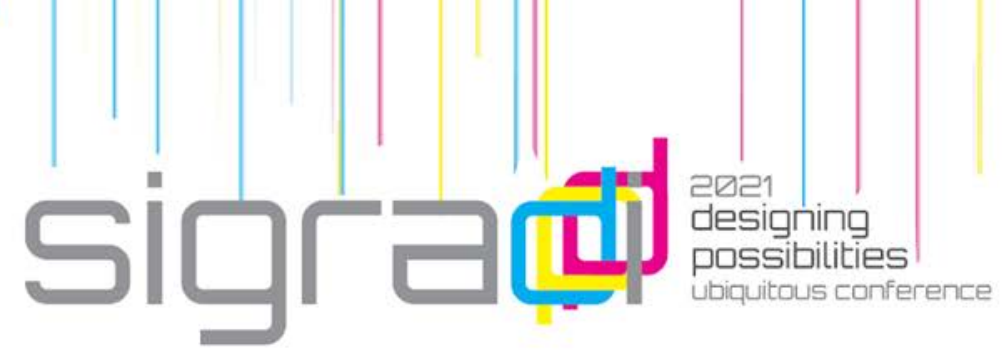

\title{
Information Design and Land Regularization: The Optimization Processes of Blueprints and Descriptive Memorials on the SIG Platform
}

\author{
Aline Feitoza de Gois ${ }^{1}$, Marcela Monteiro dos Santos², Mariana Quezado \\ Costa Lima ${ }^{3}$ \\ ${ }^{1}$ Universidade Federal do Ceará, Brasil \\ alinefeitosag@gmail.com \\ marcelamonteirosantos@gmail.com \\ marianaqcl@gmail.com
}

\begin{abstract}
Among many legal processes and political issues that hinder the Land Regularization of informal urban settlements, the delay in the production of technical documents (blueprints and descriptive memorials) and the number of errors in the systematization of information stand out. Thus, this work presents an information design methodology, aiming to optimize the documentation process through Geographic Information Systems (GIS). As a result, there was an average reduction in the production time of blueprints and memorials when compared to previous experiences of standard documentation. Errors that were still persistent were found exactly in processes that were not yet automated and needed a certain degree of mechanization. Therefore, even though the legal and political challenges seem insurmountable and need to be on the agenda, it is important to project possibilities for the technical barriers to the regularization of informal settlements, to which information design can contribute.
\end{abstract}

Keywords: Land regularization, Informal urban settlements, Information design, Geographic Information Systems, Nova Canudos

\section{Introdução}

A Regularização Fundiária abrange medidas sociais, jurídicas, urbanísticas e ambientais a serem realizadas no intuito de garantir direitos e promover uma melhor qualidade de vida à população que mora em assentamentos informais. Apesar de não se saber o número exato de famílias e domicílios marcados por 
alguma forma de irregularidade, o antigo Ministério das Cidades afirmava que mais de 12 milhões de domicílios, com famílias que possuem renda mensal de até cinco salários mínimos, encontravam-se nesta situação (Rolnik et al, 2007, 07). Logo, dado o contexto de intensa informalidade brasileira, a regularização fundiária mostra-se indispensável na busca por um desenvolvimento sustentável do espaço urbano.

A fim de garantir um processo efetivo, é necessário que a regularização fundiária faça parte de uma política urbana e seja realizada em sua integralidade. $O$ trabalho desenvolvido deve garantir a presença de diferentes agentes e ser construído a partir da multidisciplinaridade de conhecimentos. Dentre as medidas desenvolvidas, o foco do processo aqui analisado foi na titulação dos ocupantes, ou seja na garantia jurídica a continuidade do exercício do direito à moradia, ao transformar a posse em propriedade ou direito de uso (Alfonsin, 2007).

Além dos muitos processos jurídicos e das questões políticas que dificultam a regularização fundiária de assentamentos informais urbanos, será enfatizada aqui a demora na produção dos documentos técnicos (plantas e memoriais descritivos) e a quantidade de erros decorrentes de falha humana na sistematização das informações necessárias. Considerando a possibilidade de implicação de um longo tempo de espera devido aos processos judiciais/administrativos, as falhas na documentação das medições individuais podem atrasar ainda mais. Logo, ainda que os desafios jurídicos e políticos muitas vezes pareçam intransponíveis e precisem estar em pauta, é preciso projetar possibilidades para os entraves técnicos da regularização de assentamentos informais, para os quais a modelagem da informação pode contribuir.

Assim, o presente artigo procura focar no trabalho realizado por profissionais de arquitetura e urbanismo, dando ênfase à metodologia de modelagem da informação aplicada em um processo realizado na comunidade Nova Canudos, na cidade de Fortaleza, no Ceará. Esse processo foi entendido como um projeto piloto com o objetivo de otimizar a documentação, com redução do tempo de produção desses documentos e dos erros, por meio de Sistemas de Informação Geográfica (SIG), mais especificamente com uso do software livre QGIS. Embora ainda haja aprimoramentos necessários no sentido de uma maior automação do processo, a metodologia aqui apresentada teve contribuição relevante, sobretudo ao abordar a utilização da parametrização dentro de um software livre e de geoprocessamento com fins de regularização fundiária urbana de interesse social, assunto ainda pouco explorado pela literatura.

A Lei 11.888/2008, também conhecida como a Lei da Assistência Técnica à Habitação de Interesse Social (ATHIS), tem como objetivo garantir o acesso 
gratuito ao trabalho técnico de profissionais especializados, dentre eles, o serviço de arquitetura, para população de baixa renda. Entretanto, a ATHIS não tem sido aplicada de forma abrangente no Brasil. Para estimular essa aplicação, desde 2017, os Conselhos regionais de Arquitetura e Urbanismo (CAU/UF) dedicam pelo menos $2 \%$ do seu orçamento para apoiar ações de ATHIS. Embora o foco da ATHIS muitas vezes seja o de projeto e reforma, a lei também abrange a regularização fundiária de interesse social.

O processo abordado resulta de uma proposta selecionada no edital de 2020 do CAU/CE, e consistiu no levantamento de 30 Unidades Habitacionais Autônomas na Nova Canudos e na confecção de plantas baixas e memoriais descritivos para fins de regularização fundiária. Essa comunidade está localizada (Figura 1) na Zona Especial de Interesse Social (ZEIS) Bom Jardim na periferia sudoeste de Fortaleza (Ceará-Brasil).

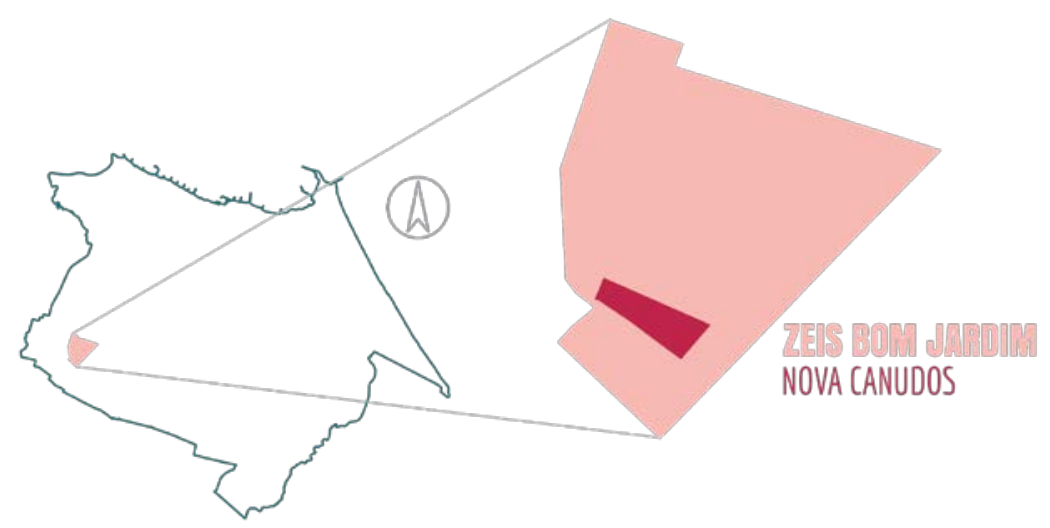

Figura 1. Localização da Nova Canudos na ZEIS Bom Jardim, em Fortaleza. Fonte: Elaboração própria com base em dados da Sefin (2010), 2020.

Compreendendo que o projeto proposto não conseguiria alcançar, em número, a elaboração dos produtos para fins de regularização fundiária do assentamento inteiro, já que moram quase 900 famílias na comunidade (PLHISFOR, 2010), optou-se pela priorização das casas de um trecho da Rua Benjamin da Silva (Figura 2). Entendeu-se que tomar como unidade espacial o eixo viário poderia reforçar laços de vizinhança e a relação existente entre os moradores e o espaço público, assim como fortalecer e facilitar a mobilização do grupo para lutas e reivindicações que vão além do acompanhamento do processo de efetivação da regularização fundiária. A escolha da Rua Benjamin da Silva se deu pela presença do centro comunitário local, Centro de Cidadania 
e Valorização Humana (CCVH), e pela relação, a partir de atividades anteriores, das autoras com alguns moradores da área, o que facilitaria o processo de diálogo e mobilização na comunidade.

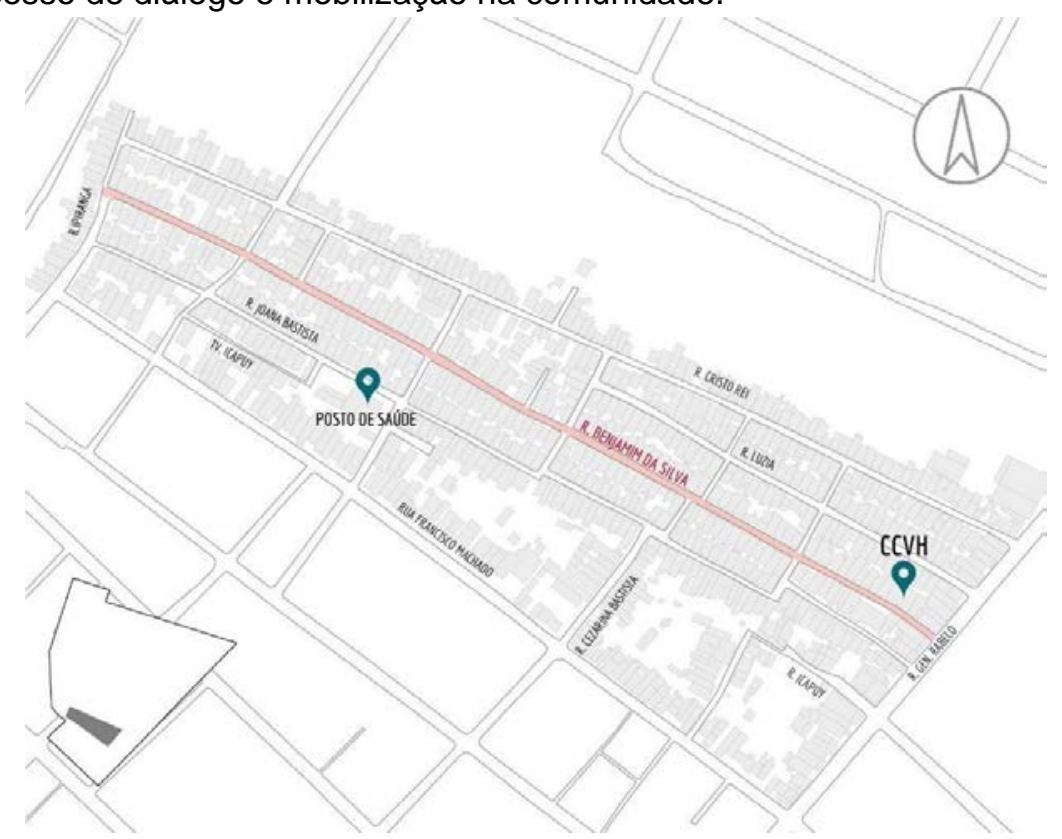

Figura 2. Localização da Rua Benjamin da Silva na Comunidade Nova Canudos. Fonte: Elaboração própria com base em dados da Sefin (2010), 2020.

Assim, o projeto foi desenvolvido de acordo com as seguintes etapas: (1) Seleção socioespacial das Unidades Habitacionais Autônomas e diálogo com os moradores; (2) Medição das Unidades Habitacionais Autônomas a serem regularizadas; (3) Confecção de Plantas e Memoriais Descritivos. No tópico a seguir, será abordado o trabalho de automatização dos documentos para fins de regularização fundiária produzidos pelo profissional de arquitetura e urbanismo.

\section{Metodologia: Elaboração de Documentos para Fins de Regularização Fundiária com Uso do SIG}

A lei 13.465 , de julho de 2017, traz na seção II, Artigo 19, parágrafo $1^{\circ}$, os elementos que devem constar na planta e no memorial descritivo: 


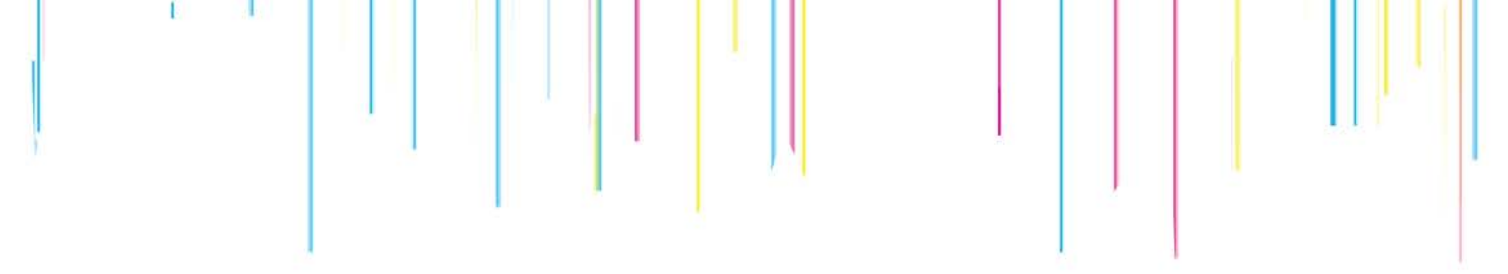

I - planta e memorial descritivo da área a ser regularizada, nos quais constem suas medidas perimetrais, área total, confrontantes, coordenadas georreferenciadas dos vértices definidores de seus limites, números das matrículas ou transcrições atingidas, indicação dos proprietários identificados e ocorrência de situações de domínio privado com proprietários não identificados em razão de descrições imprecisas dos registros anteriores (Lei n. 13.465, 2017, grifo nosso).

O processo padrão de regularização fundiária consiste no levantamento topográfico planimétrico, fechamento das quadras e poligonais dos lotes, chegando à fase de desenho e análise do polígono a ser regularizado, onde trata-se também da topologia algébrica e geométrica dos imóveis. A parte final deste processo é tradicionalmente realizada em software do tipo CAD, onde os técnicos são responsáveis por organizar todos os dados recolhidos em campo (da geometria dos lotes aos dados pessoais dos solicitantes).

A documentação das fichas e memoriais são algumas das etapas do processo de regularização fundiária que mais consomem tempo de trabalho técnico mecanizado, e onde se encontra o maior número de falhas humanas que, por sua vez, aumentam o retrabalho e, consequentemente, o tempo de conclusão do processo. Nesse sentido, tendo em vista questões como o acentuado grau de informalidade das cidades brasileiras e o longo tempo para efetivação dos processos de regularização fundiária, é necessário otimizar as várias etapas que envolvem esse trabalho. Logo, é nessa perspectiva que softwares SIG apresentam-se como ferramentas essenciais de aperfeiçoamento dessas atividades, ainda que pouco popularizadas.

Diferentemente do software CAD, o SIG possibilita coletar, armazenar, processar e analisar dados georreferenciados, integrando o levantamento e o tratamento de dados espaciais, topológicas, sociais, econômicas, entre outras. Segundo Saboya (2005), o SIG é um sistema que permite a associação de elementos com representação espacial a características não espaciais.

Assim, observando essas diferentes questões, a equipe se propôs a configurar dentro de um ambiente SIG as relações topológicas que acontecem e precisam ser documentadas em um lote a ser regularizado. É importante pontuar que se optou pela utilização de um programa Open Source, o QGIS, que é um software livre, que permite a visualização, edição e análise de dados georreferenciados. Além da redução de custos operacionais do processo, essa decisão possibilita apoiar na construção de redes informacionais, sendo capaz de alicerçar novos domínios na produção e distribuição das tecnologias, viabilizando novos modelos de relações sociais (Gregori, Camargo, \& Irigaray, 2017).

\subsection{Aproximação da Área de Atuação e Levantamento de Dados}

Compreendendo a organização estrutural do SIG como um conjunto interligado de diversos elementos e procedimentos, foi de grande importância a existência 
de uma base de lotes georreferenciada para o território em análise. Até 2019, não existia uma base de lotes da área, já que se trata de uma área que não passou por projeto formal de loteamento e sim uma ocupação informal. Entretanto, no ano em questão, essa base foi mapeada no processo do Plano Integrado de Regularização Fundiária (PIRF), considerando os lotes como sendo os terrenos as built. A partir dela, e da atuação junto a lideranças comunitárias, foi possível iniciar os trabalhos na comunidade.

No primeiro momento, foi realizado um levantamento cadastral das famílias beneficiadas, bem como a compatibilização com a base de dados oficial e na tabulação do número da casa das famílias a serem beneficiadas no processo. Para realização do levantamento cadastral, contou-se com o apoio de lideranças locais, que conheciam os moradores da rua, e procuram seguir as orientações especificadas para seleção de beneficiários, como o imóvel não ser alugado, a família morar há mais de cinco anos, entre outros critérios colocados por lei e sugeridos em diálogo com a equipe. Uma vez que o procedimento se concentrava em uma única rua, foi utilizado como número de controle das informações o número do imóvel, possibilitando valores de identificação diferenciados. Com isso, já foi possível verificar alguns imóveis que não conseguiriam se encaixar nos critérios espaciais exigidos pela legislação, como lotes maiores que $250 \mathrm{~m}^{2}$.

$\mathrm{Na}$ fase de levantamento, a equipe procurou se dividir. Uma parte em campo, trabalhando no levantamento da geometria, medidas e ângulos dos lotes cadastrados, e outra parte atuando no recolhimento dos documentos e preenchendo um formulário sobre informações sociais, que depois seriam unidas aos elementos geométricos, para gerar uma base de dados socioespacial, com a união aos dados topológicos.

Após as atividades de levantamento, cada desenho foi sistematicamente passado para um software CAD, ainda utilizado nesse primeiro momento. Nesse processo, foram verificadas possíveis pendências e inconsistências em relação às medições. Fechados os polígonos no software de desenho, os lotes e edificações foram importados para o QGIS. A partir daí, agregou-se aos elementos vetoriais as informações espaciais, físicas e cadastrais, unindo em um único arquivo base todos os dados recolhidos no processo.

\subsection{Confecção de Plantas com Informações Dinâmicas a partir da Ferramenta Atlas}

Para gerar as pranchas automaticamente, sem precisar duplicar cada uma e re-enquadrar o mapa, utilizou-se a ferramenta Atlas do software em questão. O Atlas controla os elementos dinâmicos e os elementos estáticos que digam respeito à topologia dinâmica destacada na prancha. Ou seja, sempre que é solicitado o imóvel número "xxx", ele atualiza dentro do template base o enquadramento da implantação e da planta do imóvel nas escalas préconfiguradas, e os elementos de carimbo variáveis. Elementos como nome das profissionais responsáveis e os respectivos registros na entidade classe foram 
adicionados como caixa de texto simples, assim como o título dos desenhos já que estas informações não mudam independente do lote.

A partir de um template base, essa ferramenta cria mapas dinâmicos que destacam elementos morfológicos únicos. Entregamos como input o shapefile que irá ser operado pelo atlas (os demais aparecem em todos os mapas sem filtro) e a ferramenta gera uma prancha para cada feição do shapefile. Nesse caso específico, onde nem todos os lotes foram contemplados no processo, aplicamos um segundo filtro, segundo uma coluna que diferenciava os lotes contemplados dos não contemplados. A aba saída também foi configurada de forma que o nome do arquivo que seria o output desse processo fosse 0 número do imóvel do solicitante (Figura 3).

Em seguida, foram realizadas operações para calcular as medidas necessárias e rotular com as informações exigidas por lei para o documento final da planta para fins de regularização fundiária. É importante pontuar que as operações realizadas foram controladas pela ferramenta Atlas, ou seja, cada operação será dinamicamente modificada de acordo com a feição ativa dentro do Atlas. Ao mudar a visualização no atlas (passar para a planta seguinte) ele automaticamente refaz os cálculos topológicos da nova feição, como é o caso do cálculo de medidas perimetrais.

\subsection{Confecção de Memoriais Descritivos a partir do Plugin "Azimuth and Distance Calculator"}

O memorial descritivo, por sua vez, foi desenvolvido a partir de um plugin do QGIS adaptado às nossas necessidades. O plugin original foi desenvolvido pelo geógrafo Luiz Andrade (s/d), na versão 2.0.1 do QGIS, com código-fonte disponibilizado de forma online. Como o plugin foi desenvolvido para levantamentos topográficos de grandes áreas rurais, foram necessárias algumas alterações no código para que o memorial se adequasse às demandas do cadastro fundiário urbano.

O algoritmo pede como input um polígono de partes simples, além dos dados dos confinantes, e retorna uma série de arquivos, dentre eles, destacamos o txt com o memorial descritivo analítico que faz uma descrição do polígono com seus pontos, respectivas coordenadas e azimutes, medidas perimetrais e confinantes, além do memorial descritivo sintético no formato html, que traz as mesmas informações que o output citado acima, mas no formato de tabela, o que facilita a visualização dos dados. Os dois outputs foram anexados em um compositor QGIS com os dados dos beneficiários (Figura 3). 

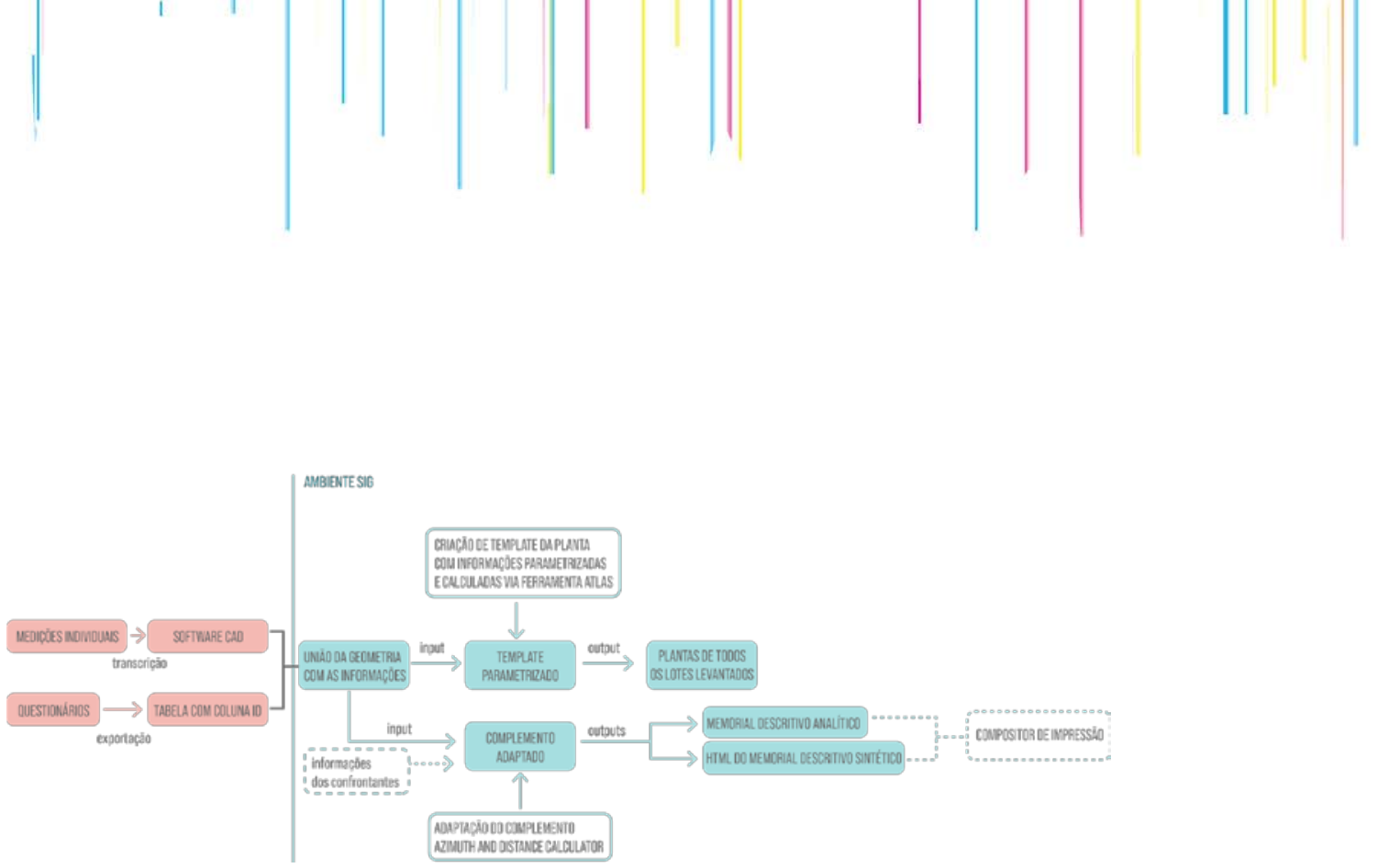

Figura 3. Método aplicado. Fonte: Elaboração própria.

\section{Resultados e Discussão}

Como resultado inicial, foi possível automatizar diversos processos normalmente manuais e repetitivos: cotas, nomenclatura dos pontos; inserção das informações do proprietário no lote; identificação de confinantes no desenho; representação da área construída; geração da prancha a partir de layout-base; enquadramento dos desenhos na prancha; preenchimento do carimbo com informações da tabela de atributos; preenchimento do cabeçalho do memorial descritivo com informações da tabela de atributos; cálculo de coordenadas, azimute e distância no memorial descritivo; geração do texto do memorial descritivo. Nesse método piloto, conseguiu-se que as plantas e seus atributos fossem todos automatizados, mas alguns processos referentes ao memorial descritivo ainda permaneceram manuais: alimentação do plugin com os dados dos confrontantes; inserção do texto do memorial analítico gerado pelo plugin no layout de impressão; inserção de foto da fachada do imóvel (não é obrigatório); inserção do $\mathrm{htm} /$ do memorial sintético no layout de impressão (não é obrigatório).

Em termos de tempo de documentação, com o método desenvolvido, plantas e memoriais descritivos de 30 lotes foram gerados (Figura 4) e corrigidos em 8 horas. A partir de experiências prévias das autoras, em um processo padrão, um cadista com domínio do processo leva entre 30 e 50 minutos por planta/memorial, a depender da complexidade geométrica do lote. Com esse piloto de automatização do processo, assim, observou-se uma redução média no tempo de produção das plantas e memoriais de $60 \%$ quando comparados ao processo de documentação padrão com plantas em software do tipo CAD e memoriais em software de texto. 

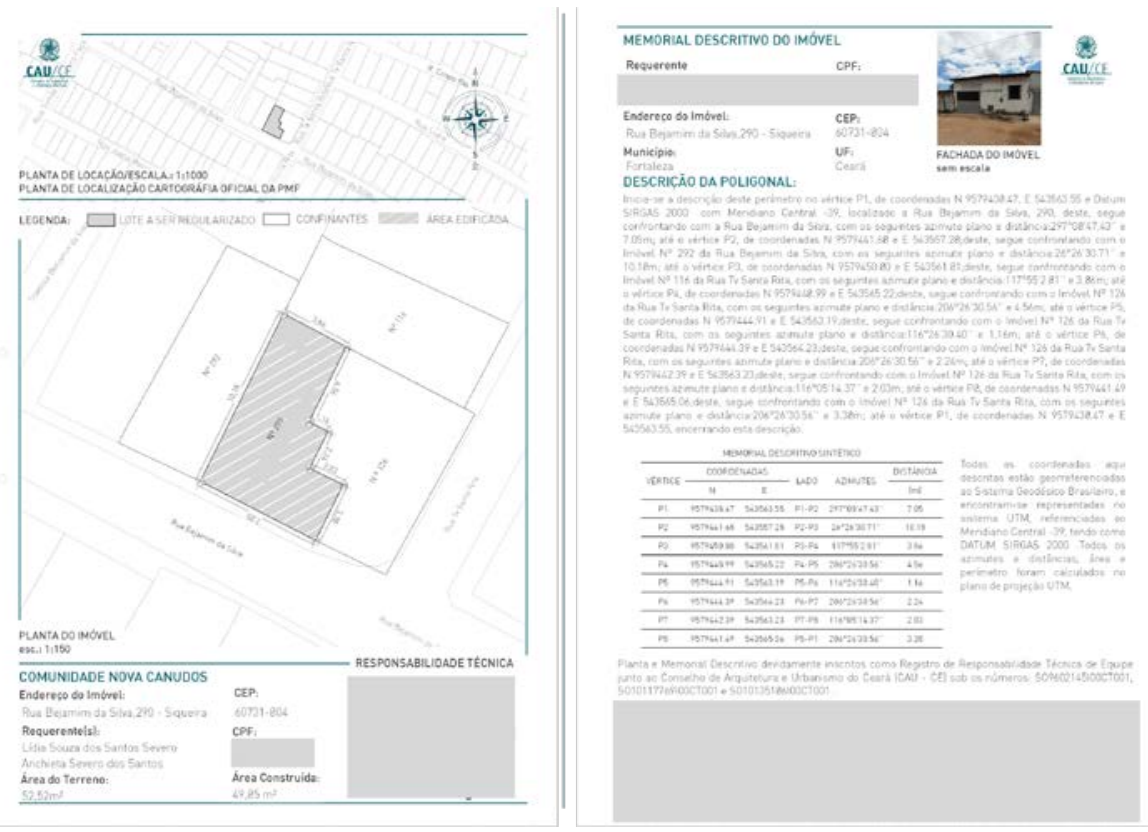

Figura 4. Exemplo de Planta e Memorial gerado. Nota: Algumas informações e assinaturas foram omitidas por questões de privacidade. Fonte: Elaboração própria.

Logo, promoveu-se a redução do tempo de documentação dos produtos e de erros decorrentes de falha humana em processos repetitivos, possibilitando assim um trabalho mais acelerado, e com possível redução de custos. Os documentos gerados corrigidos pela equipe ainda contaram com uma taxa de erro (30\% dos lotes apresentaram algum erro a ser corrigido), todos decorrentes de erro humano na alimentação do sistema. Os erros se encontravam exatamente nos processos que não foram automatizados e ainda precisavam de certo grau de mecanização.

Ressaltamos ainda a possibilidade, a partir do uso de software livre e Open Source, de construir esse conhecimento de forma colaborativa, além da ausência de custos com licença de software. Em relação ao uso do programa, destacamos a viabilidade de produção de análises socioespaciais integradas, necessárias no processo de regularização fundiária, uma vez que a regularização fundiária plena demanda, além da regularidade da posse, uma série de ações de cunho urbanístico, social e ambiental. Entretanto, esse processo carece ainda, como muitas plataformas digitais que visam a inclusão social, de uma investigação no sentido de abranger as possibilidades de participação dos moradores no levantamento das próprias casas e até mesmo na sistematização dos dados, tornando-os parte ativa também nesse processo.

O projeto apresenta grande potencialidade ao atuar no contexto de três importantes questões: (1) tentativa de apoiar na garantia da seguridade da 
do $4^{\circ}$ congresso internacional de direito e contemporaneidade. Universidade Federal de Santa Maria.

Lei n. 13.465, de 11 de julho de 2017 (2018). Dispõe sobre a regularização fundiária rural e urbana; e dá outras providências. Disponível em: http://www.planalto.gov.br/ccivil_03/_ato2015-2018/2017/lei/l13465.htm. Acesso em: 18 abr. 2021.

Lei Complementar $n^{\circ}$ 062, de 02 de fevereiro de 2009. (2009). Institui o Plano Diretor Participativo do Município de Fortaleza e dá outras providências. Disponível em: https://urbanismoemeioambiente.fortaleza.ce.gov.br/images/urbanismo-e-meioambiente/catalogodeservico/pdp_com_alteracoes_da_Ic_0108.pdf. Acesso em 10 jul. 2021.

Plano de Habitação de Interesse Social (2013). Disponível em: https://acervo.fortaleza.ce.gov.br/download-file/documentByld?id=fcd18692-a0914677-ac71-346c5cff1010. Acesso em: 10 jul. 2021.

Rolnik, R. et al. (2007) Regularização Fundiária Plena: Referências Conceituais. Brasília: Ministério das Cidades.

Saboya, R. (2005). Uma introdução aos Sistemas de Informações Geográficas no planejamento urbano, arquitextos, vitruvius, 059.10, ano 05, abr. 2005. Disponível em: https://vitruvius.com.br/revistas/read/arquitextos/05.059/479. Acesso em: 23 jun. 2021. 